\title{
Resenha
}

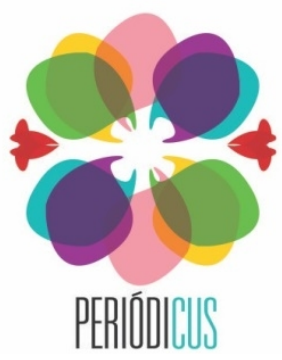

ISSN: 2358-0844

n. 14, v. 2

nov.2020-abr.2021

p. 287-291

\section{Sobre coisas que podem ser fantásticas vistas da beirada do passeio: Herbert Daniel, revolucionário e gay}

\author{
(About things that can be fantastic \\ seen from the edge of the sidewalk: \\ Herbert Daniel, revolutionary and gay) \\ (À propos de choses fantastiques \\ vues du bord du trottoir: \\ Herbert Daniel, révolutionnaire et gay)
}

Livro resenhado: GREEN, J. N. Revolucionário e gay: a extraordinária vida de Herbert Daniel - pioneiro na luta pela democracia, diversidade e inclusão. Tradução de Marília Sette Câmara. Rio de Janeiro: Civilização Brasileira, 2018. 378 p.

Alina Nunes ${ }^{1}$

Com os desdobramentos dos eventos de 1968, que ensaiaram a subversão das normas de comportamento vigentes ao redor do mundo, e a partir da terceira geração da escola dos Annales, na década de 1970, novos sujeitos e sujeitas se tornam importantes objetos de estudo para a História. Nos últimos 30 anos, cresceram exponencialmente os estudos no campo da História das Mulheres, com notáveis avanços nas pesquisas que utilizam o gênero como categoria de análise. Nesse sentido, os estudos sobre homossexualidades também têm crescido, mas, por muito tempo, estiveram restritos às áreas da sociologia e da antropologia. James Green, a partir dos anos 2000, com as pesquisas relativas ao livro Além do Carnaval: a homossexualidade masculina no Brasil do século $X X$, foi um significativo marco para a abertura de novas possibilidades para a historiografia sobre homossexualidades no Brasil. (PEDRO; VERAS, 2014)

1 Mestranda em História pelo Programa de Pós-Graduação em História da Universidade Federal de Santa Catarina (UFSC), bolsista da Fundação de Amparo à Pesquisa e Inovação do Estado de Santa Catarina (FAPESC). Graduada em História (Licenciatura e Bacharelado) pela UFSC (2019). É integrante do Laboratório de Estudos de Gênero e História (LEGH/UFSC). Desenvolve pesquisas sobre ditadura militar, história das mulheres, mulheres no audiovisual, lesbianidades e emoções. E-mail: alinanunes2@gmail.com. 
As trajetórias de James Naylor Green, o pesquisador, e de Herbert Eustáquio de Carvalho, o objeto de sua pesquisa, por pouco não se cruzaram. Green mudou-se para o Brasil em 1975, quando Herbert já estava exilado em Portugal. Herbert voltou do exílio ao fim de 1981, e Green retornou aos Estados Unidos no início de 1982. No Brasil, Green foi um dos fundadores do Somos: Grupo de Afirmação Homossexual, em 1978, que foi criado junto com a publicação de um manifesto no primeiro editorial do periódico Lampião da Esquina, intitulado "Saindo do gueto”. Herbert desenvolveu, ao longo das décadas de 1970 e 1980, suas ideias sobre os 'guetos' homossexuais, compreendendo-os como uma ferramenta de exclusão e, ao mesmo tempo, um elemento constituinte de um novo mercado capitalista.

Na introdução da obra, James Green conta que sabia quem era Herbert Daniel desde o fim da década de 1970, quando o Lampião publicou uma nota de solidariedade a ele, ainda exilado na França. O historiador, à época militante do Somos, percebeu que suas críticas às ideias da esquerda em relação às homossexualidades iam ao encontro das críticas de Daniel. Em 2008, James Green iniciou a pesquisa para o livro com uma entrevista à mãe de Herbert, dona Geny. A pesquisa seguiu por quase uma década, e serviu-se da realização de outras dezenas de entrevistas, consulta em periódicos, boletins e jornais, leitura e análise de biografias e livros de memórias, filmes e variadas fontes secundárias. As fontes integram-se de maneira orgânica à narrativa do livro, definido pelo historiador como uma biografia recuperativa, ou seja, uma biografia sobre alguém importante, porém não reconhecido.

O livro organiza-se em dezessete capítulos, cada qual designado a contar um período da vida de Herbert. Após o prólogo, assinado por Jean Wyllys, e a introdução, que explica o processo de escrita do livro, o primeiro capítulo, “Ousar lutar, ousar vencer (1992)”, abre a narrativa a partir dos últimos dias de vida do escritor mineiro, que morreu em 1992, aos 45 anos, no Rio de Janeiro. É uma maneira curiosa de abrir-se uma biografia: a partir da morte. Entretanto, é pertinente aqui trazer uma declaração de Herbert Daniel no ensaio "Notícias de outra vida”, publicado em 5 de março de 1989 no Jornal do Brasil: “Quando adoeci, uma infecção típica da aids, percebi que a pergunta a ser respondida é se há vida, e qual, antes da morte”. (GREEN, 2018, p. 310) O que importa é a vida antes da morte, e por isso, somente por isso, cabe abrir assim o livro de alguém que viveu muito antes da morte.

O segundo capítulo delineia a infância e a adolescência de Herbert, nascido em Bom Despacho, Minas Gerais, no dia 14 de dezembro de 1946. No começo da adolescência, Herbert percebeu que talvez fosse gay, e teve sua primeira relação sexual com um homem aos 16 anos. Seguiu-se a isso uma série de passeios noturnos ao Parque Municipal de Belo Horizonte, na busca de parcerias sexuais e encontros fortuitos, buscando "conservar uma meticulosa 
clandestinidade sexual” (GREEN, 2018, p. 39), vivenciando, assim, seu primeiro exílio permanecia num mundo interior, dentro do qual escondia sua sexualidade. Nos dois capítulos que seguem, Green traça as experiências de Herbert enquanto estudante da Faculdade de Medicina da Universidade Federal de Minas Gerais (UFMG), na qual ingressou em 1965. Lá, aproximou-se de estudantes que integravam o movimento estudantil, juntando-se à Polop (Organização Revolucionária Marxista Política Operária), em 1967. Foi na Polop que ele se apaixonou pela primeira vez. Erwin Resende Duarte, também militante e estudante de medicina, encantou rapidamente Herbert. Ainda que a esquerda vivenciasse uma importante reviravolta nos comportamentos durante a década de 1960, considerava a homossexualidade "produto da decadência da burguesia, que desapareceria após a queda do capitalismo”. (GREEN, 2018, p. 63) A primeira confidente de Herbert foi Dilma Rousseff, para quem o estudante conversou sobre a rejeição de Erwin. Em setembro de 1967, alguns membros líderes da Polop de Belo Horizonte romperam com a organização, formando uma outra: “O.”. Foi dentro da O. que Herbert experienciou os tumultuados acontecimentos de 1968, elaborando documentos sobre as perspectivas da luta armada no Brasil. A O. se tornou o Colina (Comandos de Libertação Nacional) no segundo semestre de 1968, fortalecendo a incipiente luta armada que tomava corpo no Brasil.

Os quatro capítulos seguintes abrangem o período em que Herbert adotou o codinome Daniel e integrou a luta armada. Em janeiro de 1969, realizou sua primeira ação armada e, no mês seguinte, entrou para a clandestinidade ao mudar-se para o Rio de Janeiro. Em abril, o Colina passou a fazer parte da VPR (Vanguarda Popular Revolucionária), que tão logo foi renomeada VAR-Palmares (Vanguarda Armada Revolucionária). Foi na VAR-Palmares que Daniel integrou os treinamentos de guerrilha rural no Vale da Ribeira ao lado de Iara Iavelberg e do comandante Carlos Lamarca, duas pessoas por quem ele nutria muito afeto e admiração. O acampamento no Vale da Ribeira foi descoberto e destruído, mas, conforme elabora Green, foi um espaço de formação muito importante para Daniel, que lá pôde pensar sobre questões relacionadas à masculinidade e sexualidade, já que se encontrava cercado pela rígida heteronormatividade vigente na esquerda armada brasileira, que almejava guerrilheiros viris, baseados no Novo Homem de Che Guevara. Em 1970, Daniel participou dos sequestros do embaixador alemão e do embaixador suíço. Entretanto, com a repressão crescente e a queda de diversos companheiros, em 1971, Daniel entrou em um período de clandestinidade muito mais severo, no qual ficava isolado durante semanas em diferentes aparelhos.

Nesse ano, Daniel conheceu Cláudio Mesquita, que faria parte de sua vida pelos próximos 20 anos. Todos os companheiros de militância de Daniel os aconselhavam a deixar o 
país: a repressão assassinava impiedosamente muitos dos seus. Em setembro de 1974, Cláudio e Herbert, juntos, atravessaram a fronteira da Argentina com passaportes falsos. Aterrissaram em Paris, mas logo foram para Portugal, que vivenciava a Revolução dos Cravos, "um contraponto otimista à recente derrota da 'via pacífica ao socialismo”” (GREEN, 2018, p. 207) experienciado no Chile. Em Portugal, Herbert trabalhou como jornalista, desenvolvendo reflexões influenciadas pelo incipiente feminismo que crescia na Europa no jornal Modas e Bordados. Em 1976, de volta a Paris, trabalhou como porteiro de uma sauna gay, um espaço que proporcionou reflexões acerca da questão dos guetos homossexuais. Foi ali que Daniel teceu suas primeiras ideias sobre identidade homossexual, uma discussão nada acalorada dentro da esquerda brasileira do período, que argumentava que essa causa era secundária e divisionista.

A lei da Anistia de 1979 não perdoou os crimes de Daniel, já que excluía os acusados de terrorismo, assalto e sequestro, forçando sua permanência no exílio até 1981. Vendo todos os seus amigos partirem de volta para o Brasil, a solidão do exílio tornou-se muito mais cruel. Depois de uma longa batalha judicial, Daniel desembarcou, em 8 de outubro de 1981, no Aeroporto do Galeão. Desde seu retorno, dedicou-se à produção intelectual, publicando três livros entre 1981 e 1983. Em seu terceiro livro, Jacarés e lobisomens: dois ensaios sobre a homossexualidade, Herbert iniciou os debates acerca do HIV e do estigma que a comunidade gay carregava sobre o vírus. Além disso, nesse livro, Herbert reiterou a necessidade do diálogo entre profissionais da saúde, pessoas infectadas e órgãos do governo para uma efetiva resposta à aids. Nessa época, Daniel conheceu Sílvia Ramos, com quem conversou a respeito de suas considerações sobre a doença. No fim de 1987, Sílvia convidou-o a integrar a Associação Brasileira Interdisciplinar de Aids (Abia), onde Daniel produziu diversos boletins informativos e ensaios em nome da associação.

Em 9 de janeiro de 1989, Herbert foi diagnosticado como soropositivo ao vírus da aids. Rapidamente, percebeu que "tinha uma nova missão: afirmar que ainda estava vivo e politizar o fato de que vivia com aids”. (GREEN, 2018, p. 309) A partir da formação do Grupo Pela Vidda, ganhou visibilidade nacional e internacional. Debatia sobre os diagnósticos de HIV que ocasionavam as "mortes civis”, a perda do direito de viver, e se contrapunha a isso afirmando o lema “viva a vida”. (GREEN, 2018, p. 311) Entre 1989 e 1991, Daniel compareceu a eventos internacionais sobre a aids, marcando o reconhecimento internacional da importância de sua militância.

Em sua última semana de vida, Daniel relatou que sonhou com Lamarca, Ângelo Pezzuti e Juarez Guimarães de Brito (companheiros da O.), três personalidades importantes na sua 
trajetória de militância que faleceram muito cedo. No dia 29 de março de 1992, Herbert Daniel faleceu no Rio de Janeiro.

Ao longo da narrativa, James Green exalta constantemente a importância do afeto e do companheirismo para a militância e resistência política. O historiador ressalta especialmente o papel das mulheres que fizeram parte da vida de Herbert Daniel, traçando retratos da força dessas pessoas que foram essenciais para que ele percorresse os caminhos que percorreu: Laís, Dodora, Zezé, Dilma, Iara, Maria Helena, Maria do Carmo e Lúcia foram algumas delas. A exaltação dessas mulheres demonstra a aproximação dos estudos sobre as homossexualidades e os estudos de gênero na historiografia.

Daniel, em carta aberta à Veja em 1981, declarou: “Costumo tentar elevar a voz, porque é preciso gritar para não esquecer uma época da qual nosso povo tem ainda tão pouca informação”. (GREEN, 2018, p. 250) Quase 40 anos depois, permanece a necessidade de elevarmos nossas vozes para falarmos sobre o período da ditadura-civil militar. Homens e mulheres, símbolos da resistência gay, da resistência lésbica, da resistência feminista, não podem ter suas vozes, mais uma vez, silenciadas. Se, no Brasil, os processos de memória da ditadura se traduzem em processos de esquecimento, em sua obra, James Green abre espaço para que pessoas como Daniel cristalizem-se na memória coletiva.

\section{Referências}

GREEN, J. N. O Grupo Somos, a esquerda e a resistência à ditadura. In: GREEN, J; QUINALHA, R. Ditadura e homossexualidades: repressão, resistência e a busca da verdade. São Carlos: EdUfscar, 2014. p. 177-200.

GREEN, J. N. Revolucionário e gay: a extraordinária vida de Herbert Daniel - pioneiro na luta pela democracia, diversidade e inclusão. Tradução de Marília Sette Câmara. Rio de Janeiro: Civilização Brasileira, 2018.

VERAS, E. F.; PEDRO, J. M. Os silêncios de Clio: escrita da história e (in)visibilidade das homossexualidades no Brasil. Tempo \& Argumento, v. 6, n. 13, p. 90-109, 2014. 